\title{
Backbone NMR resonance assignment of the Abelson kinase domain in complex with imatinib
}

\author{
Navratna Vajpai · André Strauss · Gabriele Fendrich • \\ Sandra W. Cowan-Jacob · Paul W. Manley • \\ Wolfgang Jahnke $\cdot$ Stephan Grzesiek
}

Received: 26 November 2007 / Accepted: 9 January 2008/Published online: 5 March 2008

(C) Springer Science+Business Media B.V. 2008

\begin{abstract}
Imatinib (Glivec or Gleevec) potently inhibits the tyrosine kinase activity of BCR-ABL, a constitutively activated kinase, which causes chronic myelogenous leukemia (CML). Here we report the first almost complete backbone assignment of c-ABL kinase domain in complex with imatinib.
\end{abstract}

Keywords Tyrosine kinases $\cdot$ Glivec $\cdot$ BCR-ABL . Chronic myelogenous leukemia $\cdot$ Selective labeling

\section{Biological context}

Tyrosine kinases are important mediators in signal transduction pathways and are tightly regulated by several mechanisms. Aberrant activation of these enzymes may lead to diseases, and mutations in kinase genes are implicated in many forms of cancer (Greenman et al. 2007). A number of tyrosine kinases are therefore attractive drug targets for the discovery of inhibitors, which can modulate the activity of these enzymes. The BCR-ABL fusion protein, having a constitutively activated Abelson (ABL)

Electronic supplementary material The online version of this article (doi:10.1007/s12104-008-9079-7) contains supplementary material, which is available to authorized users.

N. Vajpai · S. Grzesiek $(\bowtie)$

Biozentrum, University of Basel, Klingelbergstrasse 70,

Basel, Switzerland

e-mail: stephan.grzesiek@unibas.ch

A. Strauss - G. Fendrich $\cdot$ S. W. Cowan-Jacob .

P. W. Manley · W. Jahnke $(\bowtie)$

Novartis Institutes for Biomedical Research, Basel, Switzerland

e-mail: wolfgang.jahnke@novartis.com kinase domain, is one such important drug target, which has been clinically validated by imatinib (Glivec; Novartis Pharma AG), an efficacious and well-tolerated treatment for chronic myelogenous leukemia (CML) (Ren 2005). Much structural knowledge on ABL-inhibitor complexes has been generated using X-ray crystallography (Nagar et al. 2002; Cowan-Jacob et al. 2007), but very little is known about the solution structure and dynamics of $\mathrm{ABL}$ kinase.

To enable NMR studies on the solution behavior of ABL kinase, we have obtained backbone resonance assignment of ABL kinase domain in complex with imatinib. The selected construct of the ABL kinase domain (denoted here as ABL, residues GAMDP-S229-S500) contains 277 residues and has a typical kinase bilobal structure, with the $\mathrm{N}$-terminal lobe containing $\beta$-sheets and the conserved helix $\mathrm{C}$, and the $\mathrm{C}$-terminal lobe being mainly helical. At the interface of the two lobes is the ATP-binding pocket, which is also the binding site of most ABL inhibitors.

\section{Methods and materials}

Since ABL is not readily expressed in E. coli, we have developed a protocol for the ${ }^{13} \mathrm{C} /{ }^{15} \mathrm{~N}$ isotope labeling of the ABL kinase catalytic domain in Baculovirus-infected insect cells, either uniformly or selectively for certain amino acid types (Strauss et al. 2003; Strauss et al. 2005).

Uniformly ${ }^{13} \mathrm{C},{ }^{15} \mathrm{~N}$ or selectively labeled samples (Strauss et al. 2003; Strauss et al. 2005) of the ABLimatinib complex were prepared as $0.4 \mathrm{mM}$ solutions in $250 \mu \mathrm{l}$ (Shigemi microtubes) of buffer containing 95\% $\mathrm{H}_{2} \mathrm{O}$, 5\% $\mathrm{D}_{2} \mathrm{O}, 20 \mathrm{mM}$ BisTris, $100 \mathrm{mM} \mathrm{NaCl}, 2 \mathrm{mM}$ EDTA, $3 \mathrm{mM}$ DTT at $\mathrm{pH} 6.5$ with an ABL:imatinib ratio of 1:1. NMR spectra were recorded at $293 \mathrm{~K}$ on Bruker 
DRX 600 (cryo or room temperature probe) or DRX $800 \mathrm{MHz}$ (cryoprobe) spectrometers. Due to the lack of deuteration, the sensitivity of NMR experiments involving ${ }^{13} \mathrm{C}^{\beta}$ or other side chain nuclei was very low. Therefore, backbone assignments had to be performed with nonTROSY versions of the HNCO, HNCA, HN(CO)CA (Grzesiek and Bax 1992), and an ${ }^{15} \mathrm{~N}$-edited ${ }^{1} \mathrm{H}-{ }^{1} \mathrm{H}$ NOESY. The assignment was aided and verified by spectra of a total of 15 selectively labeled samples that had ${ }^{15} \mathrm{~N}$, ${ }^{13} \mathrm{C}^{\alpha}$ and ${ }^{13} \mathrm{C}^{\prime}$ nuclei introduced specifically for certain amino acid types (see supplementary material Table 1). All NMR data were processed and analysed using the NMRPipe (Delaglio et al. 1995) and NMRView (Johnson and Blevins 1994) software suites. ${ }^{1} \mathrm{H},{ }^{15} \mathrm{~N}$ and ${ }^{13} \mathrm{C}$ are referenced relative to the frequency of the ${ }^{2} \mathrm{H}$ lock resonance of water.

\section{Extent of assignment and data deposition}

The achieved assignments comprise $96 \%$ of all backbone ${ }^{1} \mathrm{H}^{\mathrm{N}},{ }^{15} \mathrm{~N},{ }^{13} \mathrm{C}^{\alpha}$ and ${ }^{13} \mathrm{CO}$ resonances, covering 254 of the

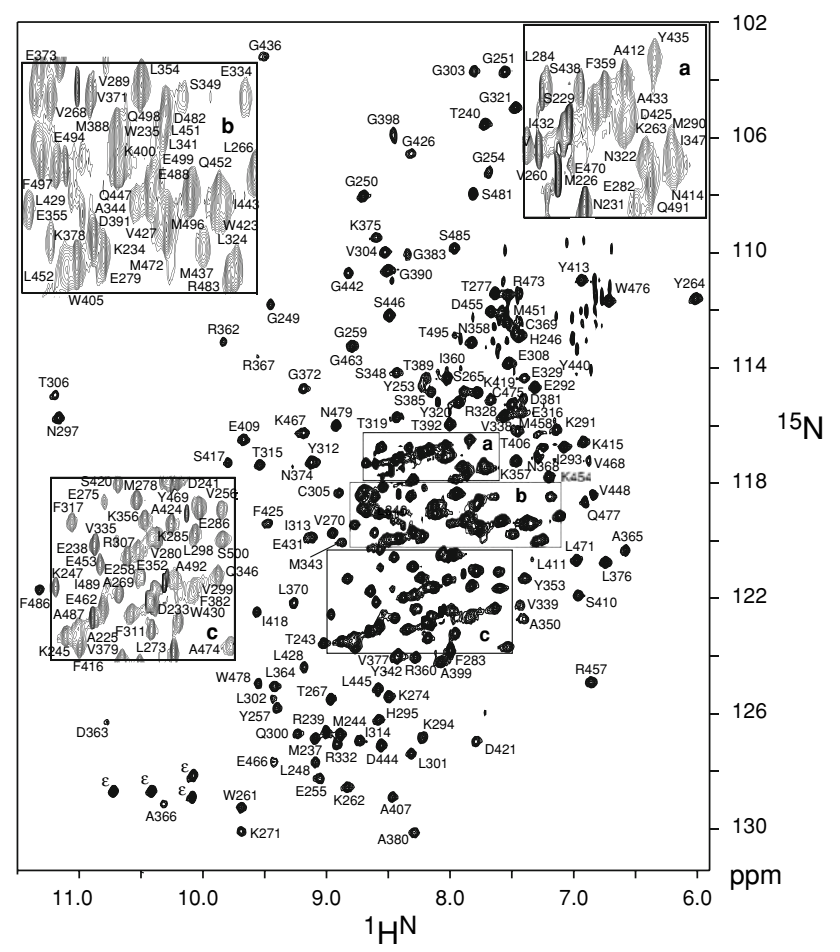

Fig. $1{ }^{1} \mathrm{H}^{\mathrm{N}}{ }^{15} \mathrm{~N}$ HSQC-TROSY (Pervushin et al. 1997) spectrum of uniformly ${ }^{15} \mathrm{~N}$-labeled ABL kinase domain-imatinib complex with assignment information. An ' $\varepsilon$ ' denotes unassigned $\mathrm{W}^{\varepsilon} \mathrm{NH}$ sidechain resonances, Subpanels a, b and c show enlarged regions of the respective rectangular boxes in the main spectrum
264 non-proline residues (Fig. 1). Unassigned residues consist of the $N$-terminal glycine, seven residues within the activation loop (consisting of residues D381-P402), and H361. Line broadening of adjacent residues indicates that most of the missing residues are broadened beyond detection due to intermediate conformational exchange. Despite the difficulty in observing the entire activation loop, the assignments include at least 14 key residues involved in ligand binding. The assignments have been deposited in the BMRB (accession number 15488).

Acknowledgements We would like to thank Drs. Sonja Alexandra Dames and Martin Allan for their help during the initial phase of the project. This work was supported by SNF grant 31-109712 (S.G.) and Novartis Pharma AG.

\section{References}

Cowan-Jacob SW, Fendrich G, Floersheimer A, Furet P, Liebetanz J, Rummel G, Rheinberger P, Centeleghe M, Fabbro D, Manley PW (2007) Structural biology contributions to the discovery of drugs to treat chronic myelogenous leukaemia. Acta Crystallogr D Biol Crystallogr 63:80-93

Delaglio F, Grzesiek S, Vuister GW, Zhu G, Pfeifer J, Bax A (1995) NMRPipe - a multidimensional spectral processing system based on unix pipes. J Biomol NMR 6:277-293

Greenman C, Stephens P, Smith R et al (2007) Patterns of somatic mutation in human cancer genomes. Nature 446:153-158

Grzesiek S, Bax A (1992) Improved 3D triple-resonance NMR techniques applied to a $31-\mathrm{kDa}$ protein. J Magn Reson 96: 432-440

Johnson BA, Blevins RA (1994) NMR View - a computer-program for the visualization and analysis of NMR data. J Biomol NMR 4:603-614

Nagar B, Bornmann WG, Pellicena P, Schindler T, Veach D R, Miller WT, Clarkson B, Kuriyan J (2002) Crystal structures of the kinase domain of c-Abl in complex with the small molecule inhibitors PD173955 and imatinib (STI-571). Cancer Res 62:4236-4243

Pervushin K, Riek R, Wider G, Wuthrich K (1997) Attenuated T2 relaxation by mutual cancellation of dipole-dipole coupling and chemical shift anisotropy indicates an avenue to NMR structures of very large biological macromolecules in solution. Proc Natl Acad Sci USA 94:12366-12371

Ren R (2005) Mechanisms of BCR-ABL in the pathogenesis of chronic myelogenous leukaemia. Nat Rev Cancer 5:172-183

Strauss A, Bitsch F, Cutting B, Fendrich G, Graff P, Liebetanz J, Zurini M, Jahnke W (2003) Amino-acid-type selective isotope labeling of proteins expressed in Baculovirus-infected insect cells useful for NMR studies. J Biomol NMR 26:367-372

Strauss A, Bitsch F, Fendrich G, Graff P, Knecht R, Meyhack B, Jahnke W (2005) Efficient uniform isotope labeling of Abl kinase expressed in Baculovirus-infected insect cells. J Biomol NMR 31:343-349 